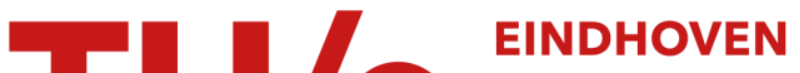 \\ UNIVERSITY OF \\ TECHNOLOGY
}

\section{Evaluation of injection systems for open tubular liquid chromatography}

Citation for published version (APA):

Claessens, H. A., Burcinova, A., Mussche, P., Tilburg, van, C. C. E., \& Cramers, C. A. (1990). Evaluation of injection systems for open tubular liquid chromatography. Journal of Microcolumn Separations, 2(3), 132-137. https://doi.org/10.1002/mcs.1220020309

DOI:

10.1002/mcs.1220020309

Document status and date:

Published: 01/01/1990

Document Version:

Publisher's PDF, also known as Version of Record (includes final page, issue and volume numbers)

Please check the document version of this publication:

- A submitted manuscript is the version of the article upon submission and before peer-review. There can be important differences between the submitted version and the official published version of record. People interested in the research are advised to contact the author for the final version of the publication, or visit the $\mathrm{DOI}$ to the publisher's website.

- The final author version and the galley proof are versions of the publication after peer review.

- The final published version features the final layout of the paper including the volume, issue and page numbers.

Link to publication

\section{General rights}

Copyright and moral rights for the publications made accessible in the public portal are retained by the authors and/or other copyright owners and it is a condition of accessing publications that users recognise and abide by the legal requirements associated with these rights.

- Users may download and print one copy of any publication from the public portal for the purpose of private study or research.

- You may not further distribute the material or use it for any profit-making activity or commercial gain

- You may freely distribute the URL identifying the publication in the public portal.

If the publication is distributed under the terms of Article $25 \mathrm{fa}$ of the Dutch Copyright Act, indicated by the "Taverne" license above, please follow below link for the End User Agreement:

www.tue.nl/taverne

Take down policy

If you believe that this document breaches copyright please contact us at:

openaccess@tue.nl

providing details and we will investigate your claim. 


\title{
Evaluation of Injection Systems for Open Tubular Liquid Chromatography
}

\author{
Henk A. Claessens, * Andrea Burcinova, and Carel A. Cramers \\ Laboratory of Instrumental Analysis, Eindhoven University of Technology, P.O. Box \\ 513,5600 MB Eindhoven, The Netherlands \\ Philippe Mussche \\ Chrompack International B.V., 4330 EA Middelburg, The Netherlands \\ Chris C.E. van Tilburg \\ VICI A.G. (Valco Europe), CH-6214 Schenkon, Switzerland
}

\begin{abstract}
The main advantages of open tubular liquid chromatography (OTLC) over conventional packed-column liquid chromatography are the gain in resolution and the increased permeability. At present the reproducible preparation of narrow-bore columns and the lack of suitable commercial chromatographic equipment delay the development of OTLC. There are stringent requirements for injectors and detectors for OTLC with respect to their volumes, geometry, and contributions to the total band broadening. In this work some properties of two different sampling systems for OTLC were studied with respect to the accuracy and repeatability of the injected volumes. An approach is presented and discussed to determine the profile factors of these injection systems.
\end{abstract}

Key words: open tubular liquid chromatography, injection systems, profile factors

\section{INTRODUCTION}

Open tubular liquid chromatography (OTLC) can be applied beneficially when columns are used that have inner diameters $<10 \mu \mathrm{m}(1-4)$. The volumes of the peaks eluted from such columns are in the nanoliter to picoliter range. This implies that high demands are placed on minimizing the chromatographic equipment's extracolumn contributions to the band broadening (5).

The potential high resolving power of OTLC gave impetus to the development of instrumentation and columns suited for OTLC (6-13). In this study two injection systems for OTLC were investigated. The moving injection technique (MIT) is based on a high-speed, electrically controlled pneumatic actuation of an injection valve that is equipped with a low-yolume (40- or $60-\mathrm{nL}$ ) internal sample loop. The loop, filled with sample, is connected with the eluent stream for a short time, thus introducing a small part of the loop contents to the top of the column $(14,15)$. Using this type of injector, volumes as low as $3 \mathrm{pL}$ can be introduced (15).

\footnotetext{
*Author to whom correspondence should be addressed
}

(C) 1990 Aster Publishing Corporation
Another injection method that has been described is the static-split (16), or pressure-pulse-driven stopped-flow injection technique (PSI) (17). Injection volumes in the $\mathrm{pL}$ range for this type of injection have been reported. Injection systems currently are evaluated by their injection-volume range and the accuracy and repeatability of the injected volumes. The injection profile factor, which reflects the peak shape of the introduced sample plug during the injection, is also of great importance. The injection profile factor depends on the injected volume, the injector geometry, and the method of injection, and can vary between the values 1 and 12 for an exponential-decay injection and an ideal sample plug, respectively (18-22). This implies that the contribution of a specific injector to the total band broadening may vary by over a factor of 10 . Therefore, it is important to improve injectors in order to decrease their contribution to the band broadening. In this study we evaluated the accuracies and repeatabilities of sample injection volumes using the MIT and PSI injection systems. The profile factors of these systems also were calculated. 
As was outlined in a previous paper (5), the total variance (in $\mathrm{cm}^{6}$ ) of a chromatographic profile in OTLC, $\sigma_{\xi}^{2}$, can be described by equation 1 :

$$
\sigma_{i}^{2}=\sigma_{\mathrm{CL}}^{2}+\sigma_{i}^{2}+\sigma_{\mathrm{D}}^{2}+\sigma_{\mathrm{e}}^{2}
$$

where $\sigma_{\mathrm{CL}}^{2}=$ variance of the OTLC column; $\sigma_{i}^{2}=V_{i}^{2} / k_{i}^{2}=$ the contribution of the sample volume, the geometry of the injector, and the method of injection (19); $\sigma_{\mathrm{D}}{ }^{2}=V_{\mathrm{D}}{ }^{2} / k_{\mathrm{D}}{ }^{2}=$ the contribution of the cell volume and the geometry of the detector; and $\sigma_{\mathbf{c}}^{2}=\tau^{2} F^{2}=$ the contribution of the electronic time constants, where $\tau$ is a time constant and $F=$ the flow rate of the eluent. Profile factors that depend on the shape of the sample plug in the injector and detector are $k_{i}^{2}$ and $k_{\mathrm{D}}{ }^{2}$, respectively.

The contribution of the chromatographic equipment, $\sigma_{\mathrm{A}}{ }^{2}$, to the total variance should not exceed $10 \%$ of the column variance. This variance can be expressed by equation 2 :

$$
\sigma_{\mathrm{A}}^{2}=\sigma_{\mathrm{i}}^{2}+\sigma_{\mathrm{D}}^{2}+\sigma_{\mathrm{e}}^{2}<0.1 \sigma_{\mathrm{CL}}^{2}
$$

From equations 1 and 2 equation 3 can be derived:

$$
\sigma_{\mathrm{P}} / \sigma_{\mathrm{CL}} \leqslant 1.05
$$

This equals a maximum loss of chromatographic resolution of $5 \%$.

To study the profile factors of the injectors, it was assumed that under constant experimental conditions the value of $\sigma_{t}^{2}$ depends on the injected volume and the shape of the injected sample plug. From this, equation 4 follows:

$$
\boldsymbol{\sigma}_{\mathrm{i}}^{2}=\left(V_{\mathrm{i}}^{2} / k_{\mathrm{i}}^{2}\right)+C
$$

where $C=$ the constant contribution of the other parts of the equipment at fixed experimental conditions.

Therefore, the plot of the experimental total variance from the OTLC chromatograms as a function of the square of the injected volumes provides information about the profile factor of a typical injector. The injector's profile factor can be calcu-

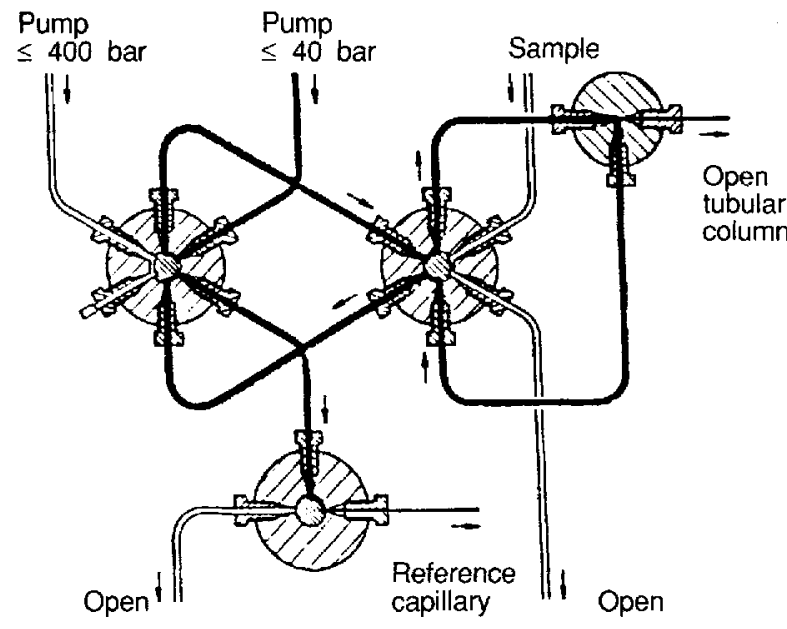

Figure 1. Schematic presentation of the PSI injector during the sample-introduction stage.

lated from the slope of these plots. Also, such plots were simulated using relevant chromatographic equations in a Pascallanguage computer program.

Experimental values for column length and diameter, eluent velocity, and capacity factors were used for these simulation calculations. Subsequently, injection volumes ranging from approximately $15 \mathrm{pL}$ to $60 \mathrm{~nL}$ and profile factors ranging from 1 to 12 were introduced in the mathematical model.

The experimental plots presented in this work also include corresponding simulated plots, including the theoretical variance of the column $\left(\sigma_{\mathrm{Cl}}{ }^{2}\right.$ ), the value $1.10 \sigma_{\mathrm{CL}}{ }^{2}$ (representing the maximum allowable contribution of the chromatographic equipment to the band broadening), and plots that represent the contribution of a typical injector as a function of the injected volumes at several values of $k_{i}^{2}$.

\begin{tabular}{|c|c|c|c|c|c|c|c|}
\hline Data set & Injector & $\begin{array}{l}\text { Column i.d. } \\
(\mu \mathrm{m})\end{array}$ & $\begin{array}{l}\text { Column Length } \\
\text { (m) }\end{array}$ & Eluent & Solute ${ }^{2}$ & Detector & $\begin{array}{l}\text { Eluent Linear } \\
\text { Velocity }(\mathrm{mm} / \mathrm{s})\end{array}$ \\
\hline I & MIT & 41 & 12.4 & $\mathrm{H}_{2} \mathrm{O}$ & 1-pentanol & FID & 17.4 \\
\hline II & MIT & 23 & 18.9 & $\mathrm{H}_{2} \mathrm{O}$ & 1-propanol & FID & 26.5 \\
\hline III & PSI & 41 & 12.4 & $\mathrm{H}_{2}^{2} \mathrm{O}$ & 1-pentanol & FID & 31.1 \\
\hline IV & PSI & 41 & 12.4 & $\mathrm{H}_{2}^{2} \mathrm{O}$ & 1-pentanol & FID & 9.8 \\
\hline $\mathrm{V}$ & PSI & 12 & 3.2 & $\begin{array}{c}\mathrm{CH}_{3} \mathrm{OH} / \mathrm{H}_{2} \mathrm{O} \\
10: 90(\mathrm{v} / \mathrm{v})\end{array}$ & fluorescein & LIFD & 6.9 \\
\hline VI & PSI & 12 & 3.2 & $\begin{array}{c}\mathrm{CH}_{3} \mathrm{OH} / \mathrm{H}_{2} \mathrm{O} \\
10: 90(\mathrm{v} / \mathrm{v})\end{array}$ & fluorescein & LIFD & 3.1 \\
\hline $\mathrm{VII}^{\mathrm{b}}$ & split & 25 & 4.5 & $\begin{array}{c}\mathrm{CH}_{3} \mathrm{OH} / \mathrm{H}_{2} \mathrm{O} \\
80: 20(\mathrm{v} / \mathrm{v})\end{array}$ & fluorescein & LIFD & 28.5 \\
\hline
\end{tabular}

The theoretical plots were compared with the plots from the chromatographic experiments and will be discussed below.

Table I. Summary of columns, injectors, detectors, and experimental conditions. 
Table II. Comparison of experimental and theoretical injection volumes for the MIT injector. ${ }^{\text {a }}$

\begin{tabular}{|c|c|c|c|c|c|}
\hline $\begin{array}{l}t_{\text {inj }} \\
\text { (s) }\end{array}$ & $\begin{array}{l}V_{\text {theor }} \\
(\mathrm{nL})\end{array}$ & $\begin{array}{l}V_{\text {exp }} \\
(\mathrm{nL})\end{array}$ & $\% D^{\mathrm{b}}$ & $\%$ RSD & $n^{\mathrm{c}}$ \\
\hline 0.024 & 0.55 & 1.24 & 125.5 & 5.52 & 6 \\
\hline 0.028 & 0.64 & 1.34 & 109.4 & 3.00 & 6 \\
\hline 0.040 & 0.92 & 1.44 & 56.4 & 4.10 & 6 \\
\hline 0.048 & 1.10 & 1.87 & 70.0 & 3.83 & 6 \\
\hline 0.056 & 1.29 & 2.13 & 65.1 & 1.05 & 6 \\
\hline 0.080 & 1.84 & 1.99 & 8.2 & 3.97 & 6 \\
\hline 0.12 & 2.76 & 2.30 & 16.7 & 1.17 & 6 \\
\hline 0.16 & 3.68 & 4.78 & 29.9 & 1.22 & 6 \\
\hline 0.20 & 4.60 & 5.34 & 16.1 & 1.03 & 6 \\
\hline 0.24 & 5.52 & 6.30 & 15.0 & 2.06 & 6 \\
\hline 0.28 & 6.64 & 6.86 & 3.3 & 0.85 & 6 \\
\hline 0.32 & 7.36 & 7.80 & 6.0 & 1.82 & 6 \\
\hline 0.36 & 8.28 & 8.48 & 2.4 & 2.73 & 6 \\
\hline 0.48 & 11.04 & 10.90 & 1.3 & 1.57 & 6 \\
\hline 0.96 & 22.08 & 21.87 & 1.0 & 1.36 & 6 \\
\hline 3.50 & 60.00 & - & - & 0.44 & 10 \\
\hline
\end{tabular}

\section{EXPERIMENTAL}

The OTLC system was equipped with a modified Haskel DSTV150 air-driven pump (Haskel, Inc., Burbank, California, USA).

The equipment for the moving injection technique consisted of a VICI AC14W.06 pneumatically actuated injector (Valco Instruments Co., Houston, Texas, USA) with an internal 60-nL sample loop. The injector was equipped with a model HSSA speed-up set, consisting of two 125A pilot valves with SQE super quick exhaust valves (all from Humphrey Products, Kalamazoo, Michigan, USA) for fast valve switching (switching times from $24 \mathrm{~ms}$ to $23 \mathrm{~s}$ ).

The pneumatic and electrical equipment for the pressurepulse-driven stopped-flow injection technique (PSI) described by A. Manz and W. Simon (17) was improved and updated. This injection system consisted of three switching valves - two VICI A-2-C6W-HC valves and one VICI A-2-C3W valve (all from VICI AG Valco Europe, Schenkon, Switzerland) equipped with speed-up sets as described above. A detailed scheme of the sample introduction stage of these injectors is outlined in Figure 1. The individual sequential steps in the injection procedure were controlled by a timer that had a resolution time $<5 \mathrm{~ms}$. The sample was introduced into the OTLC column by a second constant-pressure pump operating between 1 and 4.8 bar, depending on the sample volume to be injected.

A number of noncoated fused-silica capillaries (Chrompack International B.V., Middelburg, The Netherlands) were positioned between the injector and detector $(18.90 \mathrm{~m} \times 23 \mu \mathrm{m}$, $12.4 \mathrm{~m} \times 41 \mu \mathrm{m}$, and $3.2 \mathrm{~m} \times 12 \mu \mathrm{m})$.

The test compounds were analytical grade 1-pentanol, 1propanol (E. Merck, Darmstadt, FRG), and fluorescein (Schuchardt, München, FRG). The solvents used were deion- ized water filtered through a Milli-Q Water Purification System (Millipore, Bedford, Massachusetts, USA) and analytical grade methanol (E. Merck). Prior to use, all solvents were degassed in an ultrasonic bath. The capacity factors, $k^{\prime}$, of the test components were zero, and the diffusion coefficient, $D_{\mathrm{m}}$, of the components in the eluent $\left(10^{-9} \mathrm{~m}^{2} / \mathrm{s}\right)$ was estimated according to (2).

Two detection systems were applied. The first was a model 439 gas chromatograph equipped with a model 901 flame ionization detector (FID) (Chrompack International B.V.), in which the column outlet was inserted directly into the flame tip of the detector. The second was a laser-induced-fluorescence detector (LIFD) equipped with a Spectra-Physics (Mountain View, California, USA) model 2025-03 argon-ion light source. This detector was applied for on-column detection, giving an effective cell volume of approximately $6 \mathrm{pL}$. This optical detector system was operated at an excitation wavelength of 496 $\mathrm{nm}$ with a $515-\mathrm{nm}$ emission cut-off filter; the output power was $150 \mathrm{~mW}$. The emitted light was measured with a Hamamatsu (Toyooka-mura, Japan) model R 928 photomultiplier tube. The detector signals were recorded on a model BD 40 recorder (Kipp \& Zonen, Delft, The Netherlands).

Sample volumes ranging from $15 \mathrm{pL}$ to $60 \mathrm{~nL}$ were injected by the MIT and PSI injectors onto the various columns, which were operated at several eluent velocities. A summary of the applied columns, detectors, injectors, and experimental conditions is given in Table I.

To calculate accurate values for chromatographic peak variances and other data, the mathematical method described by Foley and Dorsey $(23,24)$ was applied and an Olivetti (Ivrea, Italy) PC M24 was used for subsequent calculations. 
Table III. Comparison of experimental and theoretical injection volumes for the PSI injector, with eluent linear velocity of $9.8 \mathrm{~mm} / \mathrm{s}^{\mathrm{a}}$

\begin{tabular}{rrrrr}
\hline $\begin{array}{r}t_{\text {inj }} \\
(\mathrm{s})\end{array}$ & $\begin{array}{c}V_{\text {theor }} \\
(\mathrm{nL})\end{array}$ & $\begin{array}{c}V_{\text {exp }} \\
(\mathrm{nL})\end{array}$ & $\% D^{\mathrm{b}}$ & $\%$ RSD \\
\hline 0.04 & 0.12 & 1.21 & 908.3 & 35.2 \\
0.08 & 0.23 & 1.15 & 400.0 & 23.8 \\
0.16 & 0.47 & 1.28 & 172.3 & 14.5 \\
0.24 & 0.70 & 1.29 & 84.3 & 13.8 \\
0.48 & 1.40 & 1.51 & 7.9 & 12.9 \\
2.14 & 6.23 & 6.91 & 10.9 & 8.4 \\
4.68 & 13.62 & 14.69 & 7.9 & 1.9 \\
9.36 & 27.24 & 27.38 & 0.5 & 4.8 \\
14.04 & 40.86 & 29.28 & 28.3 & 2.1 \\
18.07 & 52.59 & 44.50 & 15.4 & 1.3 \\
21.06 & 61.29 & 50.57 & 17.5 & 4.4
\end{tabular}

The number of experiments was six for all injection volumes. Other experimental conditions are given in the text.

'Deviation between experimental and calculated injection volumes.

A model 760 interface and model 2600 chromatography software (both from Nelson Analytical Inc., Cupertino, California, USA) were used for data acquisition and subsequent calculations. From these calculations the peak variances and asymmetry factors were taken for subsequent evaluation of the injectors. These data were used for statistical calculations of accuracy and repeatability of the injected sample volumes and for the calculations of the profile factors of the injection devices.

\section{RESULTS AND DISCUSSION}

Table II summarizes the results of the evaluation of the MIT injector. To evaluate the accuracy of the injected volumes, the experimental injection volumes calculated from the peak areas (taking the area of a full-loop injection volume as $100 \%$ ) were compared with the theoretical injection volumes. The latter could be calculated from the injection time and the eluent flow rate. The deviation between the experimental and the theoretical injection volumes is smaller than $10 \%$ when injection times longer than $280 \mathrm{~ms}$ are used. Hence, under these experimental conditions reasonable accuracy can be achieved only when injection volumes larger than $6 \mathrm{~nL}$ are introduced. Moreover, the repeatabilities of the injections were calculated and the $\%$ RSDs of the resulting peak areas were $<5 \%$.

Tables III and IV summarize the results from the evaluation of the PSI injector using eluent linear velocities of $9.8 \mathrm{~mm} / \mathrm{s}$ and $31.1 \mathrm{~mm} / \mathrm{s}$, respectively. The column $(12.4 \mathrm{~m} \times 41 \mu \mathrm{m}$, fused silica), mobile phase (deionized water), solute (1-pentanol, $k^{\prime}=0$ ), and detector (FID) were identical for both studies. The accuracy of the injection, reflected by the deviation (D), was calculated by comparing the theoretically calculated and the experimental injection volumes. The experimental injection volumes were calculated from the peak areas of these injections relative to the peak areas of full-loop injections found
Table IV. Comparison of experimental and theoretical injection volumes for the PSI injector, with eluent linear velocity of $31.1 \mathrm{~mm} / \mathrm{s}^{\mathrm{a}}$

\begin{tabular}{rrrrr}
\hline $\begin{array}{c}t_{\text {inj }} \\
(\mathrm{s})\end{array}$ & $\begin{array}{c}V_{\text {trear }} \\
(\mathrm{nL})\end{array}$ & $\begin{array}{c}V_{\text {exp }} \\
(\mathrm{nL})\end{array}$ & $\% D^{\mathrm{b}}$ & $\% \mathrm{RSD}$ \\
\hline 0.04 & 0.12 & 1.30 & 983.3 & 20.6 \\
0.08 & 0.23 & 1.73 & 652.2 & 10.0 \\
0.16 & 0.47 & 1.76 & 274.5 & 17.6 \\
0.24 & 0.70 & 1.80 & 157.1 & 9.3 \\
0.48 & 1.40 & 2.78 & 98.6 & 5.5 \\
0.96 & 2.79 & 3.99 & 43.0 & 5.0 \\
2.14 & 6.23 & 7.43 & 19.3 & 6.1 \\
4.68 & 13.62 & 14.72 & 8.1 & 3.6 \\
9.36 & 27.24 & 27.57 & 1.2 & 3.4 \\
14.04 & 40.86 & 39.56 & 3.2 & 3.2 \\
18.07 & 52.59 & 51.86 & 1.4 & 2.2 \\
21.06 & 61.29 & 60.04 & 2.0 & 3.7
\end{tabular}

"The number of experiments was six for all injection volumes. Other experimental conditions are given in the text.

${ }^{b}$ Deviation between experimental and calculated injection volumes.

using the MIT injector. The repeatabilities of the injections are presented as the \%RSDs of the measured peak areas and were $<5 \%$ when volumes $>7 \mathrm{~nL}$ were injected.

For OTLC the reproducible and accurate introduction of injection volumes ranging from $1 \mathrm{pL}$ to $1 \mathrm{~nL}$ is of particular interest. From this point of view, the above results of the MIT and PSI injector studies are not completely satisfying. This might be due to the interface between the column outlet and the FID, which was not optimal for this column type. Therefore, the same experiments were performed applying the LIFD instead of the FID. From these experiments, strongly improved data could be observed (Table V). The repeatabilities of the injections with volumes ranging from $16 \mathrm{pL}$ to $1.55 \mathrm{~nL}$ were better than $5 \%$. The results shown in Table $\mathrm{V}$ were generated using a $3.2 \mathrm{~m} \times 12 \mu \mathrm{m}$ fused-silica column and a 10:90 (v/v) methanol/water mobile phase with a linear velocity of 6.9 $\mathrm{mm} / \mathrm{s}$. The solute used was fluorescein $\left(k^{\prime}=0\right)$.

Table V. Calculated injection volumes and experimental repeatabilities for the PSI injector using LIFD."

\begin{tabular}{lll}
\hline $\begin{array}{l}t_{\text {inj }} \\
(\mathrm{s})\end{array}$ & $\begin{array}{l}V_{\text {ihcor }} \\
(\mathrm{nL})\end{array}$ & \% RSD \\
\hline 0.24 & 0.016 & 4.77 \\
1.56 & 0.104 & 2.88 \\
3.51 & 0.234 & 2.86 \\
7.02 & 0.469 & 2.79 \\
10.53 & 0.70 & 4.62 \\
17.55 & 1.17 & 1.48 \\
23.17 & 1.55 & 1.78
\end{tabular}

"The number of experiments was five for each injection volume. 


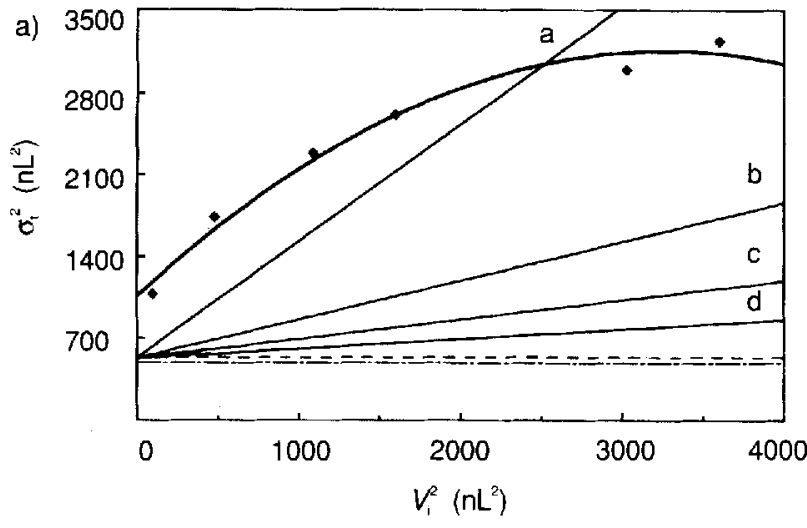

Figure 2. Plots of the total variance $\left(\sigma_{t}^{2}\right)$ versus squared injection volumes $\left(V_{i}^{2}\right)$ for a) the MIT injector, b) the PSI injector with a 12.4-m column, and c) the PSI injector with a 3.2-m column. Curves: $\bullet=\sigma_{t}^{2}$ versus $V_{i}^{2}$ (experimental); dot-dash $=$ theoretical variance of the column, $\sigma_{C L}^{2} ;$ dash = the value $1.10 \sigma_{C L}{ }^{2}$, including the $10 \%$ contribution of the chromatographic equipment to band broadening. Curves $a, b, c$, and $d$ are the theoretical contributions of the injector as a function of injected volumes for $k_{i}^{2}=1,3,6$, and 12, respectively. Conditions in a): column: $18.9 \mathrm{~m} \times 23 \mu \mathrm{m}$, fused silica; mobile phase: deionized water; solute: 1 -propanol $\left(k^{\prime}=0\right)$; detector: $F I D$; eluent linear velocity: $26.5 \mathrm{~mm} / \mathrm{s}$. Conditions in b): column: $12.4 \mathrm{~m} \times 41 \mu \mathrm{m}$, fused silica; mobile phase: deionized water; solute: 1-pentanol $\left(k^{\prime}=0\right)$; detection: FID; eluent linear velocity: $9.8 \mathrm{~mm} / \mathrm{s}$. Conditions in c): column: $3.2 \mathrm{~m} \times 12$ $\mu \mathrm{m}$, fused silica; mobile phase: $10: 90(\mathrm{v} / \mathrm{v})$ methanol/water; solute: fluorescein; detection: LIFD; eluent linear velocity: 6.9 $\mathrm{mm} / \mathrm{s}$.

In Figure 2 some of the experimental and theoretical plots of $\sigma_{1}^{2}$ versus $V_{i}^{2}$ are presented for a number of experiments for several column dimensions and operating conditions as given in the captions. In this figure, the plotted curves represent the experimental relationship $\sigma_{t}^{2}$ versus $V_{i}^{2}$. From the cotangents of these plots, the $k_{\mathrm{i}}^{2}$ value can be calculated. The dot-dash lines in the figures correspond to the theoretical variance of the various OTLC columns under the actual experimental conditions, and the dashed line includes a $10 \%$ contribution by the chromatographic equipment. The lines $\mathrm{a}, \mathrm{b}, \mathrm{c}$, and $\mathrm{d}$ represent the theoretical contribution of a typical injector at several $k_{i}^{2}$ values.

As can be observed from Figures $2 a, 2 b$, and $2 c$, the slopes of the experimental relationships of $\sigma_{i}^{2}$ versus $V_{i}^{2}$ change as a function of the injected volumes, a result which does not agree with the data from the corresponding simulation calculations.

It was noted that the experimentally observed $k_{i}^{2}$ values in these cases decreased with decreasing injection volumes, which is the opposite of what was expected. Moreover, $k_{i}^{2}$ values $<1$ were calculated for the lower range of injection volumes. The data of van Vliet (20) and Niessen (25) also show this result. From these data, we recalculated the experimental and simulation plots (Figure 3).
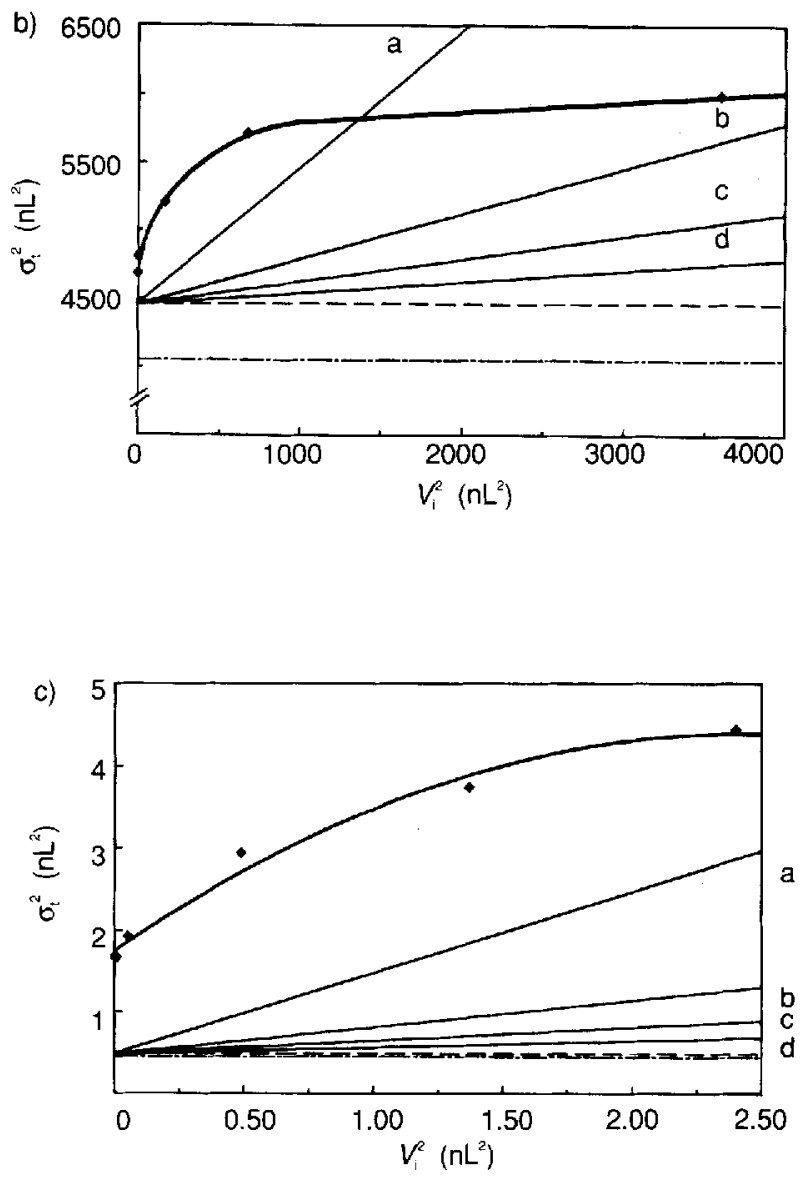

The profile factors could be estimated from the slopes of the experimental $\sigma_{\mathrm{t}}^{2}$ versus $V_{\mathrm{i}}^{2}$ plots. The results for the investigated injectors are summarized in Table VI. The experimen-

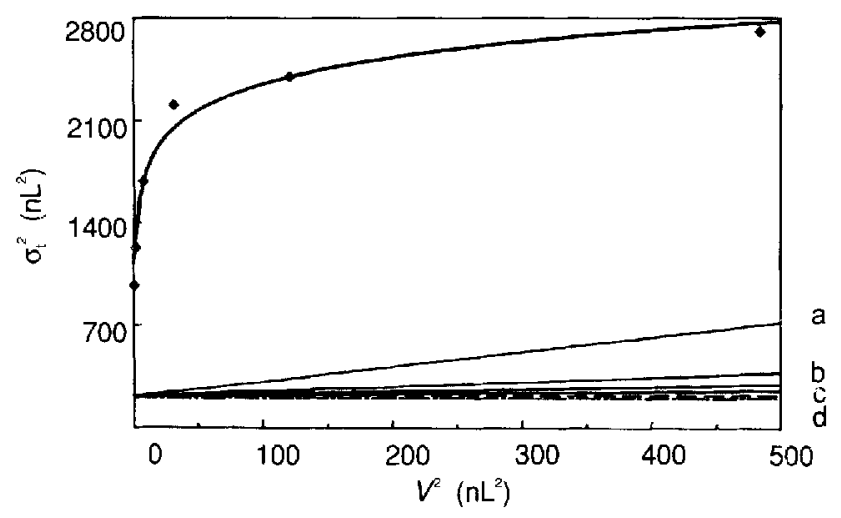

Figure 3. Plot of the total variance versus squared injertion volumes for the split injector. Curves are labied the same as for Figure 2. Column: $4.5 \mathrm{~m} \times 25 \mu \mathrm{m}$, fused silica; mobile phase: $80.20(\mathrm{v} / \mathrm{v})$ methanol/water; solute: fluorescein $\left(k^{\prime}=0\right)$; detection: LIFD; eluent linear velocity; $28.5 \mathrm{~mm} / \mathrm{s}$. 
Table VI. Summary of profile factor values calculated from the slopes of the experimental relationships of $\sigma_{i}^{2}$ versus $V_{\mathrm{i}}^{2}$ under the experimental conditions described in Table I.

\begin{tabular}{lccc} 
& $k_{i}^{2}<1$ & $1<k_{i}^{2}<6$ & $6<k_{i}^{2}<12$ \\
Data set & $V_{i}^{2}$ & $V_{i}$ & $V_{i}$ \\
\hline I & $0.5-5.1$ & $5.1-13.0$ & - \\
II & $13.0-26.0$ & $26.0-60.0$ & - \\
III & $1.2-25.5$ & $25.5-60.0$ & - \\
IV & $1.3-20.5$ & $20.5-26.5$ & $26.5-60.0$ \\
V & $0.02-1.23$ & $1.23-1.47$ & $1.47-1.55$ \\
VI & $0.02-1.27$ & $1.27-1.48$ & $1.48-1.55$ \\
VII & $0.6-11.0$ & $11.0-22.0$ & \\
a Range of injected volumes (nL). & \\
'Includes the data of van Vliet (20) and Niessen (25). \\
\multicolumn{2}{l}{}
\end{tabular}

tal results show in all cases considerably higher total variances compared to what could be expected from theory. These results indicate that the chromatographic equipment makes a high contribution to band broadening, which results in decreased efficiency. It also appears that the profile factor of a typical injector may vary widely, even over a small range of injection volumes. The data suggest that the exponential decay type of injection, corresponding to $k_{\mathrm{i}}^{2}$ value $=1$, does not fit with the shape of the injection plugs that were observed here. This observation is in agreement with the data of van Vliet (20) and Niessen (25).

The comparison of the experimental data with the simulation data proved to be very useful for the evaluation of the injection systems. Current research includes a more detailed study of the validity of the presented model for the calculation of the profile factors of injectors.

\section{ACKNOWLEDGMENT}

The authors thank Chrompack International for the research grant for this project and Valco Europe for providing the injection systems. They gratefully acknowledge Mr. B. Wanders for writing the computer program for the simulation calculations and Mr. H.E.M. van Leuken and Mr. A.J. Bombeeck for their technical assistance.

\section{REFERENCES}

1. J.H. Knox and M.T. Gilbert, J. Chromatogr. 186, 405 (1979).

2. J.H. Knox, J. Chromatogr. Sci. 18, 453 (1980)

3. G. Guiochon, Anal. Chem. 53, 1318 (1981).

4. V.L. McGuffin and M.V. Novotny, J. Chromatogr. 255, 381 (1983).

5. H.A. Claessens, M.J. Hetem, P.A. Leclerq, and C.A. Cramers, $H R C$ \& CC 11, 176 (1988).

6. D. Ishii and T. Takeuchi, J. Chromatogr. Sci. 22, 400 (1984).

7. R. Tijssen, J.P.A. Bleumer, A.C.L. Smit, and M.E. van Kreveld, J. Chromatogr. 218, 137 (1981).

8. P. Kucera and G. Guicochon, J. Chromatogr. 283, 1 (1984).

9. T. Tsuda and G. Nakagawa, J. Chromatogr. 268, 369 (1983).

10. M.J. Sepaniak, J.D. Vargo, C.N. Kettler, and M.P. Maskarinec, Anal. Chem. 56, 1252 (1984).

11. M. Krejci, K. Tesarik, M. Rusek, and J. Pajurek, J. Chromatogr. 218, 167 (1981).

12. F.J. Yang, J. Chromatogr. Sci. 20, 241 (1982).

13. O. van Berkel, H. Poppe, and J.C. Kraak, Chromatographia 24, 739 (1987).

14. M.C. Harvey and S.D. Stearns, Anal. Chem. 56, 837 (1984).

15. M.C. Harvey, S.D. Stearns, and J.P. Averette, LC, Liq. Chromatogr. HPLC Mag. 3, 5 (1985).

16. J.W. Jorgenson and E.J. Guthrie, J. Chromatogr. 255, 335 (1983).

17. A. Manz and W. Simon, J. Chromatogr. 387, 187 (1987).

18. J.C. Stemberg, in Advances in Chromatography, vol. 2, J.C. Giddings and R.A. Keller, Eds. (Marcel Dekker, New York, 1966), p. 205.

19. G. Guiochon and H. Colin, J. Chromatogr. Libr: 28, 1 (1984).

20. H.P.M. van Vliet, Thesis, University of Amsterdam, 1986.

21. M.C. Harvey and S.D. Steams, J. Chromatogr. Sci. 21,473 (1983).

22. J.C. Gluckman and M. Novotny, J. Chromatogr. Sci. 23, 57 (1985).

23. J.P. Foley and J.G. Dorsey, Anal. Chem. 55, 730 (1983).

24. J.P. Foley and J.G. Dorsey, J. Chromatogr. Sci. 22, 40 (1984).

25. W.M.A. Niessen, Thesis, University of Amsterdam, 1986. 